\title{
Environmental Health Officer's Knowledge of Sensory Deprivation Tanks in BC
}

Alyssa Zambon ${ }^{1}$, Helen Heacock ${ }^{2}$

1 Lead author, B. Tech Student, School of Health Sciences, British Columbia Institute of Technology, 3709 Willingdon Ave, Burnaby, BC V5G 3H2

2 Supervisor, School of Health Sciences, British Columbia Institute of Technology, 3709 Willingdon Ave, Burnaby, BC V5G 3H2

\begin{abstract}
Background and Purpose: Personal service establishments are abundant such as piercing shops, tattoo parlours, spas and now float spas. Sensory deprivation tanks were popular in the 1980s and have come back as a new way to relax, reduce pain and relieve stress and to provide a complete deprivation of the senses. The sanitation of these tanks have caused concern in the public health field as bacteria and parasites can easily live and proliferate in the tank water. Environmental Health Officers (EHOs) have to keep up to date with new or returning technology in order to provide information to the public and to ensure their safety. This research project investigated EHOs with differing years of employment in the field, geographic working location and age and their knowledge of sensory deprivation tanks.
\end{abstract}

Methods: A survey created in Google Forms and Survey Monkey was disseminated through e-mail who then forwarded an e-mail to all EHOs in BC. The survey asked demographic questions, health and safety, sanitation and disinfection and general knowledge of floatation tanks. A t-test and ANOVA was used to analyze the data.

Results: Three comparisons were tested: first was the number of years an EHO has worked in the field and their test score; second was their age and test score; and last was their geographic location and test score. The null hypotheses were not rejected as the pvalue was found to be greater than 0.05 for all of the variables analyzed.

Discussion: Overall, there was weak knowledge in EHOs and due to the small sample size there was weak statistical significance between the associations found regarding the number of years an EHO has worked in the field, their age and geographic location where they work compared to their test scores.

Conclusion: More information needs to be provided to all EHOs to keep them updated on new personal service establishments.

Keywords: Floatation tanks, sensory deprivation tanks, environmental health officer, knowledge, $\mathrm{BC}$, public health, personal service establishments, PSE, float tank, REST tank, isolation tank

\section{Introduction}

Flotation tanks are increasing in popularity. With just a quick Google search one will notice several float spas (approximately eleven) available in the Metro Vancouver area. The idea behind these isolation tanks is to completely deprive oneself of all senses (1). The tanks are kept close to body temperature. There is no light, sound or smell in the tank; complete isolation (1). What completes the sensation is that one is floating in $30-45$ centimeters of water fully saturated with pounds of dissolved magnesium sulphate (Epson salts), causing the person to simply float in the tank further enhancing the sensory deprivation $(2,3)$. Flotation tanks are also referred to as sensory deprivation tanks, restricted environmental stimulation technique (REST) tanks or isolation tanks.

This floating practice is used in complementary and alternative medicine therapies to help reduce stress and pain by 
decreasing blood pressure, muscle tension and heart rate (4). Some individuals use it to increase their well-being or enhance their creativity by entering an altered state of consciousness (4). There is increasing evidence about the successful use of isolation tanks in chronic pain therapy, Asperger syndrome and attention deficit hyperactivity disorder (ADHD) (4).

The literature surrounding the psychological and physiological aspects of floating date back to the 1950s, however, information regarding the sanitation is significantly lacking. Disinfection is important in water as it eliminates many potential pathogens which include Escherichia coli, cryptosporidium, and Pseudomonas aeruginosa $(5,6)$. These are commonly implicated in warm recreational water and are rapidly spread. E. coli and cryptosporidium can cause prolonged diarrhea (5). P. aeruginosa causes

dermatitis/folliculitis, a skin infection, resulting in a rash which can lead to pus-filled blisters (6).

Environmental Health Officers (EHOs) inspect personal service establishments (PSEs) which flotation tanks fall under, but are lacking legislation and guidelines regarding disinfection as this is industry has recently experienced renewed interest. Due to this revival of the industry EHOs may not have the necessary knowledge specific to the tanks. Sensory deprivation tanks should follow disinfection protocols as they are not immune to bacteria. The water in these tanks is filtered in between floaters and the water is completely changed approximately every ten weeks (7). Float House, a flotation tank spa in the Vancouver Coastal Health (VCH) district indicate on their website that they are required to use a disinfectant, "bromine", in accordance with VCH (7). Research is being done on the sanitation of these tanks and a recent guideline has been developed.

\section{Evidence Review}

\section{General Recreational Water Disinfection}

The primary contamination of recreational waters is from feces which can result in infection when disinfection is not adequate enough $(5,8)$. Potential microbial hazards include viruses, bacteria, protozoa, and fungi $(5,8)$.

To control these microorganisms, chlorination or bromination (supplemented with other disinfection) along with filtration is recommended (8). Supplemental forms of disinfection include: ozone, and ultraviolet radiation (8). The levels of these disinfectants vary across countries but the basic principles remain the same: have disinfection and have residual in the water to maintain disinfection levels when new contamination arises. The World Health Organization states that free chlorine (chlorine residual left in the water) should be no higher than 3 ppm in public pools, no higher than $5 \mathrm{ppm}$ in hot tubs with the $\mathrm{pH}$ between 7.2-7.8 (8).

Another common disinfectant is bromine, the total concentration should not exceed 4 ppm in public pools and should not exceed 5 ppm in hot tubs with the $\mathrm{pH}$ between 7.2-8.0 (8). Looking at these concentrations the sensory deprivation tanks should be close to the hot tub range as the temperature in a tank tends to be higher than $32^{\circ} \mathrm{C}$.

The last disinfectant that has been suggested for sensory deprivation is hydrogen peroxide (9). The WHO does not list recommended levels because it is only used in small systems (8). This information gives a basic outline for disinfection but only applies to recreational water that is not saturated with magnesium sulphate which can change the water chemistry thus potentially changing the disinfectant properties. An examination of the literature available for isolation tanks was looked at through Canada, other countries and lastly BC guidelines. 


\section{Canadian Legislation and Guidelines}

Health Canada does not have any legislation or guidelines for sensory deprivation tanks, they only have guidelines for infection prevention in terms of tattooing, body piercing and electrolysis (10). PSEs are governed at the provincial level in Canada (10). Only Alberta and Manitoba have legislation for PSEs other provinces do not have guidelines or legislation towards sensory deprivation tanks.

Alberta: Alberta Health developed "Health Standards and Guidelines for Personal Services" in 1995 (11). Their concern was all areas in personal service establishments as the transmission of infectious agents and blood borne agents is high (11). For sensory deprivation the organism of concern is Pseudomonas. The guidelines are outdated but are vague and open to interpretation allowing them to be adapted for modern times.

They classify items that need disinfection, sterilization and/or cleaning into three categories of critical, semi-critical and noncritical (11). Sensory deprivation tanks can fall into non-critical. Non-critical are items that come in contact with the body but do not penetrate the skin. This would include the tank as it should never be penetrating skin and causing harm in that sense. For non-critical items the guidelines recommend a low level of disinfection (11). Disinfectants that are considered low level are QUATS which does not appear to be adequate enough to destroy Pseudomonas and fecal bacteria while providing a residual in the water. The guidelines do not discuss sensory deprivation tanks directly and are more focused on tattooing and piercing.

Alberta also has the "Personal Services Regulation" which is open to interpretation and mostly contains general information about sanitation and duties (12). Alberta also has related guidelines; however, they are only for tattooing, electrolysis, barbering and hairstyling, esthetics and piercing.

Manitoba: "Personal Service Facility Guidelines" is the document used in Manitoba. It was established in 2013 and is 21 pages long and only mentions floatation tanks in their list of types of personal services (13). Similar to the Alberta guidelines and regulations this document is vague and open to interpretation. This document delves into a variety of topics such as documentation and record keeping, construction and design, maintenance, and disinfection (13). They also follow the WHO's document about the classification of items for disinfection (13).

Winnipeg has a regulation called the "Body Modification By-Law" which comes up when searching for sensory deprivation tank regulations in Manitoba. This document though only sees body modification as tattooing, piercing (not including ears), scarification, implant insertion (14). Other than these two documents, Manitoba does not have any other information regarding isolation tanks.

\section{Other Countries}

Australia: Australia has an extensive document for PSEs covering a wide range of establishments. Additionally where this publication is located there are information sheets for clients (15). Their "Health Guidelines for Personal Care and Body Art Industries" may cover a lot of areas but their flotation tank section is only a brief paragraph.

It is found that the main infection risk for flotation tanks is the salty water that is reused in between clients (15). Therefore, both internal and external surfaces should be kept clean and abrasive cleaners should not be used as they can cause corrosion due to the high concentration of salt (15). It also includes a statement regarding checking the filters and conducting regular maintenance, something 
that has not been seen in the previous guidelines that have been examined (15). It also links to part A: 4.2.2 of the document which is routine cleaning of work surfaces (15). This is to ensure the tank is properly maintained and that gloves are routinely changed along with towels.

Lastly the guidelines bring up that when oils and creams are applied to help protect the skin that appropriate dispensing procedures should be followed (15). Dispensing of liquids is gone into further detail in part A: section 2.5 of dispensing (15).

In the "Health Information Sheet for Flotation Tanks for Clients" it is a small section broken down into what a flotation tank is and what the operator is required to do (16). The 'operator requirements' is a summary of what is found in the guideline about maintenance, cleanliness and the dispensing of oils and creams (16).

United States of America: Similar to Canada, the USA does not have federal regulations or standards regarding not just sensory deprivation tanks but all areas of PSEs. These regulations are up to individual states and only California and Virginia have regulations and bills. The National Sanitation Foundation (NSF) was established at the University of Michigan: School of Public Health (17). The NSF is non-governmental but helps develop standards for public health officials to ensure safety for the public (17). Secondly, the Floatation Tank Association is working to develop a set of standards for health departments to follow when inspecting float spas (18).

The NSF standards for flotation tanks are based on product manufacturers and public health official opinions as well as their own expertise in spas and other recreational waters (2). The standards list twenty points, several related to the design criteria for the tank. In regards to disinfection NSF recommends following the manufacturer's cleaning process and that disinfection should be completing a minimum 3-log reduction of two different microorganisms (2). Having a supplement treatment system such as ozone or UV light is recommended (2). If ozone is used then offgassing should be monitored and tested regularly (2). An interesting aspect that NSF has included is that if an operator chooses to only do the supplementary disinfection that they can achieve the 3-log reduction (2). The entire treatment system (filtration and disinfection) should have a minimum of a 3,000 hour life testing where it still achieves the 3-log reduction (2). These standards are extensive and detailed and provide alternatives for those who do not want to use strong chemicals. The standards are still being modified to incorporate experience and knowledge from other groups involved in flotation tanks.

The Floatation Tank Association (FTA) has a different idea regarding standards. The FTA is a community who is making recommendations for best practices regarding flotation tanks by setting out guidelines that they wish will be used around the world (18). The group is not government run and provides simple standards that require no chemical disinfection from chlorine or bromine (9). They rely entirely on hydrogen peroxide, filtration between clients, ozone and UV and state that the high concentration of salt and dark environment prevents the growth of bacteria (9). The water shall be kept at $<200$ $\mathrm{CFU}$ aerobic plate count with no total coliforms according to the FTA (9). The standards for hydrogen peroxide is $20-100$ ppm with an ideal range of $30-40 \mathrm{ppm}$, ozone is a maximum of $0.05 \mathrm{ppm}$ (9). This association contradicts what the health authorities and the NSF say. 
BC Guidelines: British Columbia is similar to the other provinces and countries in that there is no legislation directly towards sensory deprivation tanks. However, in January 2016 a guideline was completed regarding sensory deprivation tanks called the 'Guidelines for Floatation Tanks'. The Regulated Activities Regulation in the Public Health Act in Part 2: Division 1 addresses PSEs (19).

The regulation is short and only addresses the need for an adequate supply of hot and cold water, or hand washing facility, minors being prohibited from tanning facilities, and signs needed for tanning facilities (19). This regulation does not provide EHOs with any support when they are in the PSEs, this is why guidelines have been used to accompany this.

"The Guidelines for Personal Service Establishments" in $\mathrm{BC}$ is similar to the previous guidelines. Nothing directly discussing isolation tanks only suggestions for preventing health hazards, general sanitation of critical and non-critical items, and infection control (20). EHOs established a set of guidelines dedicated to flotation tanks because the information that is available to work with is very minimal.

The 'Guidelines for Floatation Tanks' was written by the Health Protection Branch and Ministry of Health (21). It was developed through the health authorities, Ministry of Health and with industry input. For disinfection the guidelines recommend automatic disinfection equipment be installed in the flotation tank with chlorine (free chlorine must be between 3ppm-5ppm and combined chlorine less than $1 \mathrm{ppm}$ ) or bromine (concentration between 5ppm-8ppm) being used as primary disinfection (21).

Supplementary disinfection (ozone and UV) is recommended to improve water quality but should not replace primary disinfectant (21). Filtration is required and should be able to complete three turnovers between clients, this means that the water in the tank is being replaced once every five minutes (21). What is interesting and differs from the FTA is that these guidelines do not recommend hydrogen peroxide as it has limited ability in controlling bacteria (21). These guidelines will be a useful tool for EHOs when performing inspections and plan approval.

\section{Purpose}

The purpose of this research study was to examine environmental health officers' knowledge about sensory deprivation tanks. Specifically, this study compared knowledge of EHOs who have been in the field less than five years to the knowledge of those who have been in the field for five years or more. Additional comparisons of age and geographic location was conducted.

\section{Methods}

A questionnaire was developed using Google Forms and Survey Monkey. The survey was emailed to Gordon Moseley, President Elect for BC Branch of CIPHI who then sent it out to all EHOs who are CIPHI members across all health authorities in BC. The e-mail had a script in the message along with the link to the survey. The survey had a cover letter and the consent form followed after. If the respondent chose "no" on the consent form then the survey took them directly to the end where a "thank you for participating" message appeared. If they chose to respond the survey commenced.

The survey's first component contained demographic questions that asked age, how long they have been working in the field, the type of area they work in (whether rural, semiurban or urban) and gender. The next section asked fifteen questions on general knowledge, sanitation and disinfection and health and safety of the tanks. 
From the fifteen questions, fourteen of them had correct and incorrect answers and one was excluded as the answer was not clear. A score was given for the number of correct answers. The answers were automatically saved in Google Forms and Survey Monkey which were accessed and exported into Microsoft Excel. That data was formatted and inputted into Statistical Analysis System (SAS).

\section{Results}

The study data was analyzed using a twotailed t-Test and ANOVA in SAS. All data collected in Google Forms and Survey Monkey was exported to Excel where descriptive statistics were done and the raw data was formatted for SAS analysis.

Descriptive Statistics: An overall summary score of all of the respondents was conducted and it was found that the mean score was 7.6 correct responses out of 14 questions (approximately 54\%) among 33 participants. The lowest score achieved was a 4 out of 14 (approximately 29\%) and the highest score was 12 out of 14 (approximately 86\%). The standard deviation (SD) was 2.0. No outliers were indicated as the lowest score of 4 was achieved twice and the highest score was not unrealistic.

For knowledge scores and the number of years an EHO has worked in the field the mean score for those who had less than five years' experience was 7.0 and for those with more than five years' experience the mean score was 8.0. There were more respondents in the more than 5 years' experience group (21 participants) than the less than 5 years' experience group (12 responses). The SD was 1.9 and 2.0 respectively. Test scores and the age of the respondents were compared in two ways. First they were broken up into five different age categories which were 20-30 years, 31-40 years, 41-50 years, 51-60 years and 61 year and over. The number of respondents in each group were low with 11 in the first group then in order of increasing age 9 responses, 7 responses, 3 responses and 3 in the last group. The mean scores between these age groups increases up to the 51-60 bracket and then decreases slightly in the $61+$ group, the means were $7.2,7.6,7.7,8.3,8.0$ with increasing age brackets (See Graph 1). The SDs were 1.8, 2.2, 2.6, 1.1 and 2.0 for increasing age brackets.

Age groups were then condensed into two categories, 20-40 years and 41 years and older. This increased the number of respondents for the two groups (20 in the first group and 13 in the second). The means still had the increase with a mean score of 7.4 in 20-40 years group and a mean score of 7.9 in the 41 years and older group. The SD was 2.0 and 2.1

respectively again indicating wide variation around the mean.

Lastly, the knowledge scores were compared to the different geographic locations of urban, semi-urban and rural. As expected urban had a higher mean score of 8 followed by semiurban with 7.4 and rural with 7. The SDs were again high indicating variation around the mean at 1.6 for urban, 2.7 for semi-urban and 2.1 for rural. Participant numbers were higher in urban at 16 responses and 8 responses were in the semi-urban and rural groups. Only 32 of the total 33 participants were used in this analysis as the one respondent chose "Other" as their geographic location, since they were the only one they were excluded.

Inferential Statistics: Data from the survey was inputted into Excel which was formatted into two columns for SAS analysis. A twotailed t-Test was conducted on ages that had been condensed into two categories ( 21 to 40 years and $41+$ years) with knowledge scores. Another two-tailed t-Test was done on number of years the EHO has worked with knowledge scores. Lastly, a parametric ANOVA was used on geographic location and knowledge scores as well as full age ranges and knowledge scores. 


\begin{tabular}{|l|l|l|}
\hline Comparison & Test & p-value \\
\hline $\begin{array}{l}\text { Knowledge } \\
\text { and Number } \\
\text { of years } \\
\text { worked }\end{array}$ & t-test & 0.1879 \\
\hline $\begin{array}{l}\text { Knowledge } \\
\text { and } \\
\text { Condensed } \\
\text { Ages }\end{array}$ & t-test & 0.4284 \\
\hline $\begin{array}{l}\text { Knowledge } \\
\text { and All Ages }\end{array}$ & ANOVA & 0.9416 \\
\hline $\begin{array}{l}\text { Knowledge } \\
\text { and } \\
\begin{array}{l}\text { Geographic } \\
\text { Location }\end{array}\end{array}$ & ANOVA & 0.5071 \\
\hline
\end{tabular}

T-Test Analysis of Test Scores and Number of Years Worked in the Field: A two-tailed t-Test was chosen for the analysis of the numerical knowledge score and number of years worked in the field. A test for normality was completed and all p-values were above 0.05 indicative that the data was normally distributed, therefore, the independent samples t-test was used. The p-values was 0.1879 , which is above the acceptable limit $(p<0.05)$ therefore the null hypothesis was not rejected. T-Test Analysis of Test Scores and Age: A two-tailed t-Test was chosen for the analysis of numerical knowledge scores and the two condensed age groups (21-40 years and 40+ years). A test for normality resulted in $\mathrm{p}>0.05$ therefore, the independent samples t-test was used. The $\mathrm{p}=0.4284$ which is above the 0.05 limit. Therefore, the null hypothesis was not rejected.

ANOVA Analysis of Test Scores and Age: An ANOVA test was conducted for knowledge scores and all age groups as there were more than two categories. A goodness of fit test was conducted for normal distribution and all $\mathrm{p}$ values were greater than 0.05 therefore, a parametric ANOVA was chosen. The p-value was greater than the acceptable limit of 0.05 $(p=0.9416)$ therefore, the null hypothesis was not rejected.

\section{ANOVA Analysis of Test Scores and} Geographic Location: A goodness of fit test was conducted for the analysis of knowledge scores and the three types of geographic locations. It was found the results were normally distributed and a parametric ANOVA was chosen. The p-value was greater than 0.05 at $p=0.5071$ therefore the null hypothesis was not rejected.

\section{Discussion}

All three null hypotheses were not rejected as the $p$-value was larger than 0.05 . It is important to note that although the null hypotheses was not rejected there is still the potential that these results could be impacted by the small sample size. Some important information was extracted from the results that may help to drive further research. The scores for all respondents was relatively low with only an average score of $54 \%$. This is just barely a pass in most institutions and is indicative that EHOs in all areas need to enhance their knowledge in this area. Overall the knowledge of EHOs was low and there were no associations between age, years worked and geographic locations and the scores attained.

\section{Number of Years Worked in the Field and} Knowledge Scores: For knowledge scores and the number of years an EHO has worked in the field those who had less than five years experience had a lower score (7.0) compared to EHOs more than five years experience (8.0). If there were more participants this could indicate that those who are just entering the field may need to do more research into this area. Also this may be a result of newer EHOs potentially being overwhelmed with information and still learning the field.

Age and Knowledge Scores: When the knowledge scores were compared to age there is a steady increase of the mean score from the age group 21-30 years old to the 51-60 years old group, then there is a small drop in mean score for the 61 years and older group. This 
could be indicating a relationship between age and knowledge if more participants were in each test group. The increase in age is similar to that of the number of years an EHO has worked in the field, as those who are older will have been in the field far longer than younger EHOs. The decrease in knowledge scores for those in the 61 years and older group could be because this group is starting to retire or are retired, meaning they are no longer invested in learning about newer PSEs.

Geographic Location and Knowledge Scores:

The last comparison for knowledge scores was on the geographic location that EHOs worked in. This was divided by rural, semi-urban and urban. It would be expected that those living in urban environments would have a higher level of knowledge of float tanks as the businesses are located in urban centers. This was seen in the mean scores where in urban it was 8 , semiurban was 7.4 and rural had a mean score of 7 . If there was a larger sample size this difference may have been more pronounced and shown to have statistically significant associations.

\section{Recommendations}

Health Authority: Based on this study it is recommended that health authorities stay up to date with newer technologies in all fields including PSEs. This could be done by providing an online forum where EHOs can contribute ideas, or new information about the various areas in public health. Additionally, health authorities should make frequent announcements about new guidelines, legislation or information being produced for EHOs to access. Another way this could be done is by requiring EHOs to take mandatory courses online about newer technologies with short tests at the end of each module.

However, this can be time consuming and may create too large of a workload for EHOs.

By staying up to date, EHOs can discover public health problems more rapidly during an inspection and they can provide accurate information to the public about health risks.
The public will acknowledge the EHOs as being a knowledgeable authority figure whom they can rely on for accurate information.

Current Study: It is also highly recommended to allot more time to developing a thorough and comprehensive survey as well as allowing more time for response collection. If possible, it would be ideal to have access to the e-mails of all EHOs so that reminder e-mails could be sent out.

Producing a larger survey that is more comprehensive and reflective of the new BC guidelines will demonstrate if the scores were a result of the low number of questions offered, meaning the EHOs weren't given a large enough opportunity to demonstrate their knowledge, or if the obtained knowledge score from this study was accurate.

\section{Limitations}

The limitations surrounding this study were that, the requirement that e-mailed surveys be sent through another person (Gordon Moseley, BC CIPHI Branch, President) and insufficient time. By having to e-mail the survey through someone else instead of distributing a mass email to all EHOs in $\mathrm{BC}$ it prevented the distribution of reminder e-mails to complete the survey. Reminder e-mails are necessary to remind individuals to conduct the survey as the original could have been easily lost or forgotten. Insufficient time was the largest limitation of this study as it impacted the collection period and the ability to develop a standardized questionnaire. This study was only given a few months to prepare, distribute and collect results, therefore, more time would allow for an increase in responses.

Additionally, if more time was allotted then a standard questionnaire could have been developed and the rigour of the questionnaire could have been established.

It was noted that one question which asked "Some float spas do not want to use chlorine or bromine because they think:" This question can be answered solely based on opinions of 
the EHOs as no evidence is clear on what the actual reasons are. Therefore, this question was eliminated from the statistical analysis. In the end there were only 14 knowledge questions that were used, this could have impacted the results as it does not provide a large variety.

\section{Future Research}

Examination of the actual sensory deprivation tank water would be an ideal direction to take. This will help to provide data regarding the types of microorganisms present in the water. Additional studies could include inoculating tank water with microorganisms and then examining various disinfectants over a range of differing concentrations to determine the best disinfectant for the tanks.

A replication of this study could also be conducted but with a more robust survey. Also, managers, operators and employees of float spas could be surveyed and compared to EHO knowledge. Or an opinion survey of disinfection and float spas between EHOs and the employees of float spas. Currently there is only 12 float spas in Metro Vancouver, therefore, this may be problematic but with their increase in popularity could lead to more spas opening up.

\section{Conclusions}

Results indicated overall weak knowledge in EHOs in BC regarding health and safety of floatation tanks. There were weak statistically significant associations between knowledge and the variables compared which could be reflective of a small sample size. Additionally, the survey itself should incorporate more questions as this could have also been a cause of the results.

\section{Acknowledgements}

The authors thank the British Columbia Institute of Technology, Environmental Health department for supporting their research. Also special thanks to Shelley Beaudet at Vancouver Coastal Health for allowing the researchers access to the draft copy of the Floatation Guidelines and for the idea to study this topic.

\section{Competing Interest}

The authors declare that they have no competing interest.

\section{References}

(1) Vancouver Metro. Sensory deprivation tanks making a comeback [Internet]. 2003 May 9 [cited 2016 Apr 10]. Available from: http://www.metronews.ca/news/vancouver/201 3/05/10/sensory-deprivation-tanks-making-acomeback.html

(2) NSF. NSF International Special Insert 2014 Fall Edition [Internet]. 2014 [cited 2016 Apr 10]. Available from: http://www.nsf.org/media/enews/documents/A I_Staying_Afloat.pdf

(3) Turkewitz, J. Climb in, tune in: A renaissance for sensory deprivation tanks. The New York Times [newspaper on the Internet]. 2015 Oct 17 [cited 2016 Apr 10]. Available from http://www.nytimes.com/2015/10/18/us/climbin-tune-in-a-renaissance-for-sensorydeprivation-tanks.html

(4) Jonsson K, Kjellgren A. Curing the sick and creating supermen - How relaxation in flotation tanks is advertised on the Internet. European Journal of Integrative Medicine [Internet]. 2014 Oct [cited 2016 Apr 10]; 6(5):601-609. Available from ScienceDirect with Full Text:

http://www.sciencedirect.com/science/article/p ii/S1876382014000845?np=y

(5) Centers for Disease Control and Prevention. Recreational Water Illnesses (RWIs) [Internet]. 2015 Feb 5 [cited 2016 Apr 10]. Available from: 
http://www.cdc.gov/healthywater/swimming/r wi/

(6) Centers for Disease Control and Prevention. "Hot Tub Rash" (Pseudomonas Dermatitis/Folliculitis) [Internet]. 2014 Apr 15 [cited 2016 Apr 10]. Available from: http://www.cdc.gov/healthywater/swimming/r wi/illnesses/hot-tub-rash.html

(7) Float House. Frequently Asked Questions [Internet]. n.d. [cited 2016 Apr 10]. Available from: http://www.floathouse.ca/frequentlyasked-questions/

(8) World Health Organization. Guidelines for safe recreational water environments volume 2 swimming pools and similar environments [Internet]. 2006 [cited 2016 Apr 10]. Available from:

http://www.who.int/water_sanitation_health/ba thing/srwe2full.pdf

(9) Floatation Tank Association. Float Tank Standard [Internet]. n.d. [cited 2016 Apr 10]. Available from:

http://www.floatation.org/resources/healthinfo/ health-standard/

(10) Rideout K. Comparison of Guidelines and Regulatory Frameworks for Personal Service Establishments [Internet]. National Collaborating Centre for Environmental Health. 2010 July [cited 2016 Apr 10]. Available from:

http://www.ncceh.ca/sites/default/files/PSE_G uidelines_Comparison_Table_July\%202010.p df

(11) Alberta Health. Health Standards and Guidelines for Personal Services [Internet]. 1995 Oct [cited 2016 Apr 10]. Available from: http://www.calgaryhealthregion.ca/publichealt $\mathrm{h} /$ envhealth/pdf/legislation/PersonalServicesPt 1.pdf
(12) Province of Alberta. Personal Services Regulation [Internet]. 2014 Aug 12 [cited 2016 Apr 10]. Available from: http://www.qp.alberta.ca/documents/Regs/200 3_020.pdf

(13) Manitoba Health. Personal Service Facility Guidelines [Internet]. 2013 Nov [cited 2016 Apr 10]. Available from: https://www.gov.mb.ca/health/publichealth/en vironmentalhealth/protection/docs/psf_guideli ne.pdf

(14) The City of Winnipeg. Body Modification By-Law No. 40/2005 [Internet]. 2006 Jan 1 [cited 2016 Apr 10]. Available from: http://clkapps.winnipeg.ca/dmis/docext/viewd oc. asp?documenttypeid $=1 \&$ docid $=2065$

(15) Communicable Disease Control Section, Department of Human Services. Health guidelines for personal care and body art industries [Internet]. 2011 Jul 12 [cited 2016 Apr 10]. Available from: https://www2.health.vic.gov.au/getfile/?sc_ite $\mathrm{mid}=\%$ 7bB4C5BD13-8452-4597-966B6496C97C4C2E\%7d\&title=Health\%20guideli nes $\% 20$ for $\% 20$ personal $\% 20$ care $\% 20$ and $\% 20 \mathrm{~b}$ ody\%20art\%20industries\%20(Full\%20copy)

(16) Department of Human Services. Health information sheets for clients: Solaria, saunas, flotation tanks and gymnasiums [Internet]. 2011 Jul 12 [cited 2016 Apr 10]. Available from

https://www2.health.vic.gov.au/getfile/?sc_ite $\mathrm{mid}=\%$ 7b9D589542-4B9B-418F-820BA374DC76A4F0\%7d\&title=Health\%20inform ation $\% 20$ sheets $\% 20$ for $\% 20$ clients $\% 20$ Solaria,\%20saunas, \%20flotation\%20tanks\%20 and\%20gymnasium

(17) Regulatory Resources. NSF [Internet]. n.d. [cited 2016 Apr 10]. Available from: http://www.nsf.org/regulatory/ 
(18) About FTA. Floatation Tank Association [Internet]. n.d. [cited 2016 Apr 10] Available from: http://www.floatation.org/aboutfta/

(19) Queen's Printer. Regulated Activities Regulation [Internet]. 2011 Sept 9 [cited 2016 Apr 10] Available from:

http://www.bclaws.ca/civix/document/id/comp lete/statreg/161_2011\#division_d2e68

(20) Ministry of Health and Ministry Responsible for Seniors. Guidelines for Personal Service Establishments (PSEs) [Internet]. 1995 Aug [revised 2000; cited 2016 Apr 10]. Available from:

http://www.health.gov.bc.ca/library/publicatio ns/year/2000/pse.pdf

(21) Health Protection Branch: Ministry of Health. Guidelines for Floatation Tanks [Internet]. 2016 Jan [cited 2016 Apr 10]. 